\title{
Article \\ Effects of Germination Black Soy Milk Fermented with Lactobacillus plantarum TWK10 on Anti-Oxidative and Anti-Melanogenesis
}

\author{
Te-Hua Liu ${ }^{1,+}$, Wei-Ting Chiang ${ }^{1,+} \mathbb{D}$, Meng-Chun Cheng ${ }^{2,3, *}$ and Tsung-Yu Tsai ${ }^{1, *}$ \\ 1 Department of Food Science, Fu Jen Catholic University, New Taipei City 242062, Taiwan; \\ 147848@mail.fju.edu.tw (T.-H.L.); chiangw6@msu.edu (W.-T.C.) \\ 2 College of Human Ecology, Fu Jen Catholic University, New Taipei City 242062, Taiwan \\ 3 Department of Food Science, Nutrition, and Nutraceutical Biotechnology, Shih Chien University, \\ Taipei City 104336, Taiwan \\ * Correspondence: mccheng@g2.usc.edu.tw (M.-C.C.); tytsai@mail.fju.edu.tw (T.-Y.T.); \\ Tel.: +886-2-2538-1111 (ext. 6228) (M.-C.C.); +886-2-2905-2539 (T.-Y.T.) \\ + These authors contributed equally to this work.
}

check for updates

Citation: Liu, T.-H.; Chiang, W.-T.; Cheng, M.-C.; Tsai, T.-Y. Effects of Germination Black Soy Milk Fermented with Lactobacillus plantarum TWK10 on Anti-Oxidative and Anti-Melanogenesis. Appl. Sci. 2022, 12, 277. https://doi.org/ 10.3390/app12010277

Academic Editor: Wojciech Kolanowski

Received: 20 November 2021 Accepted: 19 December 2021 Published: 28 December 2021

Publisher's Note: MDPI stays neutral with regard to jurisdictional claims in published maps and institutional affiliations.

Copyright: (c) 2021 by the authors Licensee MDPI, Basel, Switzerland. This article is an open access article distributed under the terms and conditions of the Creative Commons Attribution (CC BY) license (https:// creativecommons.org/licenses/by/ $4.0 /)$.

\begin{abstract}
Black soybean germination or fermentation increases active ingredient bioavailability and anti-oxidative activity. This study investigated the effects of fermented and germinated black soy milk on anti-oxidation and melanogenesis inhibition. The total phenolic content (TPC; $42.66 \pm 1.65 \mathrm{mg}$ gallic acid equivalent/g) and total flavonoid content (TFC; $5.43 \pm 0.54 \mathrm{mg}$ quercetin equivalent (QE)/g) in ethanol extracts from Lactobacillus plantarum TWK10 (TWK10)-fermented nongermination black soy milk (FNGB) were significantly $(p<0.05)$ higher than those in ethanol extracts from nonfermented-nongermination black soy milk (NNGB). Although the TPC of ethanol extracts from nonfermented-germination black soy milk (NGB) and fermented-germination black soy milk (FGB) were not significantly different $(p>0.05)$, the TFC of FGB $(1.79 \pm 0.08 \mathrm{mg}$ QE/g) was significantly higher than that of NGB $(p<0.05)$. The 1,1-diphenyl-2-picrylhydrazyl radical scavenging activity of ethanol extracts from NNGB, FNGB, NGB, and FGB was significantly higher than that of water extracts at $10 \mathrm{mg} / \mathrm{mL}(p<0.05)$. Furthermore, ethanol extracts from both FNGB and FGB significantly reduced the melanin content in zebrafish embryos at $100 \mu \mathrm{g} / \mathrm{mL}(p<0.05)$ without causing death, malformation or bradycardia. Overall, the antioxidant activity of black soy milk significantly increased after TWK10 fermentation; moreover, ethanol extracts from FNGB and FGB could inhibit melanogenesis, indicating their potential as whitening ingredients.
\end{abstract}

Keywords: Lactobacillus plantarum TWK10; germination black soy milk; antioxidative; melanogenesis; zebrafish embryos

\section{Introduction}

Melanin biosynthesis is an important metabolic process in the body. It has been demonstrated that melanocytes generate melanin that determines the color of skin, hair, and eyes in humans [1,2]. Melanogenesis is a complex, multi-step procedure. Under physiological conditions, melanin production is advantageous because of the protective effects of melanin against pernicious ultraviolet radiation. However, excessive melanin biosynthesis causes hyperpigmentation, which results in various dermatological conditions such as freckles, age spots, melasma, and even skin cancer [3,4]. Several studies have indicated that tyrosinase, a copper-containing enzyme, is extensively found in living organisms and is the pivotal rate-limiting enzyme in melanin biosynthesis. The hydroxylation of L-tyrosine to L-dihydroxyphenylalanine (DOPA) and the oxidation of DOPA to dopaquinone are catalyzed by tyrosinase [5-7]. Further, an increase in tyrosinase activity promotes melanin biosynthesis, as do excessive UV irradiation and oxidative stress. Kao 
et al. demonstrated that melanogenesis could be inhibited by reducing intracellular oxidative stress [8]. Several animal models are used to study the inhibition of melanogenesis, such as zebrafish, mice, rats, guinea pigs, or humans. Recently, because melanin is present on the surface of zebrafish embryos and the process of pigmentation can be easily observed without complicated experimental steps, numerous studies have used zebrafish embryos for melanin-related experiments [9]. Detection of important indicators that affect melanogenesis, such as tyrosinase activity, in the zebrafish embryo model is also feasible [10]. In addition, the appearance of zebrafish embryos and heart rate can also be used to evaluate the toxicity of samples [9]. Because of these advantages, this study used the zebrafish embryo model in in vivo experiments.

Black soybeans are rich in bioactive compounds such as isoflavones, anthocyanins, and saponins, which are beneficial to human health [11]. Several studies have indicated that black soybeans can prevent low-density lipoprotein oxidation, lower cholesterol levels, scavenge free radicals, and enhance gastrointestinal function [12,13]. During germination, the metabolism, structure, and gene expression of black soybean undergo changes [14]. The enzymes in black soybeans are activated by germination to enhance the nutritional value and promote the bioavailability of functional components [15,16]. Bueno et al. established that germination not only significantly increased the anti-oxidant activities of black soybeans, but also enhanced the production of phenols and other anti-oxidant components such as peptides without aromatic amino acids [17]. In addition, fermentation could also improve the nutritional value and beneficial bioactivities of black soybean products [18]. Juan and Chou indicated that the 1,1-diphenyl-2-picrylhydrazyl (DPPH) radical scavenging and $\mathrm{Fe}^{2+}$ chelating activities of fermented black soybeans extract were significantly better than those of unfermented black soybeans extract [19]. Moreover, the inhibitory effect of black soybeans on tyrosinase activity in vitro were also significantly improved after fermentation [20]. Studies have indicated that glycosyl isoflavones in soy milk are hydrolyzed to deglycosylated isoflavones by $\beta$-glucosidase from lactic acid bacteria (LAB). Therefore, the content of bioactive ingredients in soy milk is increased by fermentation with $\mathrm{LAB}$, which could significantly reduce the carbohydrates that cannot be absorbed by humans.

Lactobacillus plantarum TWK10 (TWK10) was isolated from Taiwanese pickled cabbage in our lab [21]. TWK10 fermented soy milk has been shown to display many beneficial bioactivities including anti-hypertension [22], anti-oxidation, promotion of wound healing [23] and improvement of hypertension- or diabetes-associated dementia [24,25]. Cheng et al. demonstrated that after TWK10 fermentation, the contents of deglycosylated isoflavones in soy milk were significantly increased along with its health benefits [26]. However, few studies have investigated the antioxidative or anti-melanogenesis abilities of germinated black soy milk used as a fermentation substrate. Therefore, this study investigated the effects of black soy milk germination or fermentation on its anti-oxidation and anti-melanogenesis activities in a zebrafish embryo model.

\section{Materials and Methods}

\subsection{Material}

TWK10 was preserved at the Bioresource Collection and Research Center (BCRC, Hsinchu, Taiwan), under the number BCRC910734. The reagents DPPH, aluminum chloride (AlCl3), bovine serum albumin, chloroform, ethanol, Folin \& Ciocalteu's phenol, gallic acid, phenylthiourea, sodium carbonate, sodium chloride, and quercetin were purchased from Sigma-Aldrich Corporation (St. Louis, MO, USA). Bacto-agar and Lactobacilli MRS broth were purchased from BD Co. (Franklin Lakes, NJ, USA).

\subsection{Animals}

Wild-type zebrafish embryos were purchased from the Taiwan Zebrafish Core FacilityNational Health Research Institutes. The animal use protocol in this study was reviewed and approved by the Institutional Animal Care and Research Ethics Committee of Fu Jen 
Catholic University (IACUC approval No: A10813). The morphology of growing zebrafish embryos was observed, and all experiments were conducted $7 \mathrm{~h}$ post fertilization (hpf) and were performed as previously described with slight modifications $[7,27]$.

\subsection{Black Soybean Germination}

Black soybeans (Glycine max (L.) Merr.) were purchased from Chuan Gui Bio-Organic Co., Ltd. (Taoyuan City, Taiwan). Subsequently, $100 \mathrm{~g}$ of black soybeans were washed three times with deionized water and ultrasonicated with $500 \mathrm{~mL}$ of deionized water for $10 \mathrm{~min}$ for thorough cleansing. Thereafter, the black soybeans were then soaked in $6 \%$ $\mathrm{NaOCl}$ solution for $30 \mathrm{~min}$ to eliminate the residual microorganisms. The soaked black soybeans were cleaned several times with deionized water to remove $\mathrm{NaOCl}$ odor. Finally, the soybeans were soaked in $500 \mathrm{~mL}$ of sterile water for $4 \mathrm{~h}$ to soften the testa. According to the process described in previous studies $[28,29]$ with some modifications, the black soybeans were drained and then layered on an iron plate with a layer of gore. The plates were then covered with a sheet of aluminum foil to ensure complete darkness, and the black soybeans were sprouted in an incubator at $25^{\circ} \mathrm{C}$ for $72 \mathrm{~h}$. The sprout length of black soybeans were measured from the root to the base of the cotyledon by using a ruler before they were freeze dried. The dried sprouts were then stored at $4{ }^{\circ} \mathrm{C}$ until further use.

\subsection{Preparation of Black Soy Milk and Extracts}

The method used to obtain black soy milk and extracts herein was based on previous studies with some modifications [21,24]. Briefly, the nongerminating or germinating black soybeans soaked in water (1:5 w/w, dry sprouts basis) for $12 \mathrm{~h}$ were ground in a food blender and filtered through a defatted cotton sheet, and then, the solution was reclaimed. Finally, the degree Brix was adjusted to $10 \%$ using water to complete the preparation of nongermination or germination black soy milk. The nongermination or germination black soy milk was then sterilized using pasteurization at $70^{\circ} \mathrm{C}$ for $20 \mathrm{~s}$, cooled to $37^{\circ} \mathrm{C}$, inoculated with $1 \% v / v$ TWK10 suspension, and fermented at $37^{\circ} \mathrm{C}$ for $48 \mathrm{~h}$. For preparing nonfermented-nongermination black soy milk, the purchased black soybeans were cleaned according to the steps in Section 2.3. Then, the cleaned black soybeans were soaked and ground, and the degree Brix was adjusted to $10 \%$ as mentioned earlier.

After fermentation, the product was freeze-dried (SDF-25 freeze-dryer, Chang Jung Business Co., Feng-Jen, Taiwan) to obtain a dry powder, which was subjected to extraction with $120 \mathrm{~mL}$ of sterile water or $170 \mathrm{~mL}$ of $95 \%$ ethanol in a $37^{\circ} \mathrm{C}$ water bath for $30 \mathrm{~min}$. Next, the extracts were agitated in a rotary shaker at $120 \mathrm{rpm}$ and $37^{\circ} \mathrm{C}$ for $30 \mathrm{~min}$. The mixtures were centrifuged at $4{ }^{\circ} \mathrm{C}$ and $12,000 \times g$ for $30 \mathrm{~min}$ to obtain the supernatant. The resulting supernatants were dried in vacuo and stored at $-30^{\circ} \mathrm{C}$. Before the subsequent experiments, the water extract and ethanol extract were re-dissolved in sterile water and DMSO, respectively, to formulate different concentrations of extracts. The extracts of nonfermented-nongermination black soy milk (NNGB), fermented-nongermination black soy milk (FNGB), and nonfermented-germination black soy milk (NGB) were prepared using the same method described above.

\subsection{Measurement of LAB Count, $p H$ Value and Titratable Acidity}

The LAB number, $\mathrm{pH}$, and titratable acidity of nongermination black soy milk or germination black soy milk at $0,12,24,36,48,60$, and $72 \mathrm{~h}$ after fermentation with TWK10 were determined. Briefly, samples from FNGB and fermented-germination black soy milk (FGB) were obtained at the aforementioned time and serially diluted 10 times with sterile $0.85 \%$ saline. Subsequently, $1 \mathrm{~mL}$ of appropriate dilutions was plated on MRS agar plates and incubated at $37^{\circ} \mathrm{C}$. After $48 \mathrm{~h}$, the microbial colonies on the plates were counted.

For determination of $\mathrm{pH}$ and titratable acidity, samples were collected in a centrifuge tube and centrifuged for $10 \mathrm{~min}$ at $4{ }^{\circ} \mathrm{C}$ and $4000 \times g$ to obtain the supernatant. The $\mathrm{pH}$ of supernatant was measured using a pH meter (SP-701, Mettler Co., Columbus, OH, USA). Part of the supernatant was titrated with $0.1 \mathrm{~N} \mathrm{NaOH}$, which was standardized by using 
KHP to pH 8.3 (end point). Equivalent weight of lactic acid was used to calculate total titratable acidity using the following equation: $(\%)=(\mathrm{A} \times \mathrm{F} \times 0.009 / \mathrm{S}) \times 100$, where $\mathrm{A}$, $\mathrm{F}$, and $\mathrm{S}$ represent the titrated volume $(\mathrm{mL})$ of $0.1 \mathrm{~N} \mathrm{NaOH}$, factor of $0.1 \mathrm{~N} \mathrm{NaOH}$, and volume $(\mathrm{mL})$ of sample, respectively.

\subsection{Measurement of Total Phenolic Content (TPC)}

The TPC was evaluated based on the methods described in previous studies, with some modifications [30,31]. A total of $50 \mu \mathrm{L}$ of the extract was mixed with $1000 \mu \mathrm{L}$ of deionized water and $500 \mu \mathrm{L}$ of Folin \& Ciocalteu's phenol reagent in a 15-mL centrifugation tube. Next, $2500 \mu \mathrm{L}$ of $10 \% \mathrm{NaCO}_{3}$ solution was added to the tubes and the solution was mixed. The mixture was then incubated at room temperature in the dark for $20 \mathrm{~min}$, and the absorbance was measured at $735 \mathrm{~nm}$. Gallic acid was used as the standard, and TPC was calculated as mg gallic acid equivalent (GAE)/g of extracts in this study.

\subsection{Measurement of Total Flavonoid Content (TFC)}

The levels of flavonoids in all extracts were determined based on a colorimetric assay described by Kao et al. and Zhao et al. with slight modifications [32,33]. Briefly, $2000 \mu \mathrm{L}$ of the extracts were mixed with $120 \mu \mathrm{L}$ of $5 \% \mathrm{NaNO}_{2}$. After standing at room temperature for $5 \mathrm{~min}, 240 \mu \mathrm{L}$ of $10 \% \mathrm{AlCl}_{3}$ was added and made to react for $5 \mathrm{~min}$. Next, $1.2 \mathrm{~mL}$ of $1 \mathrm{M}$ $\mathrm{NaOH}$ and $200 \mu \mathrm{L} \mathrm{CHCl}_{3}$ were added to the mixture and mixed to homogeneity. Finally, the tubes were centrifuged at $10,000 \times g$ for $1 \mathrm{~min}$, and the supernatant was collected for measuring the absorbance at $510 \mathrm{~nm}$. Quercetin was used as the standard, and TFC was calculated as mg quercetin equivalent (QE)/g of extracts in this study.

\subsection{Measurement of Anti-Oxidation Activity}

The DPPH radical scavenging activity was used to evaluate the anti-oxidation properties of all extracts, as described by Yamaguchi et al. and Zhao et al. with slight modifications $[32,34]$. Different concentrations of extracts $(100 \mu \mathrm{L})$ were added to $500 \mu \mathrm{L}$ of $0.1 \mathrm{mM}$ DPPH solution and mixed. After incubation at room temperature for $1 \mathrm{~h}$ in the dark, the absorbance of each mixture was measured at $517 \mathrm{~nm}$.

\subsection{In Vivo Zebrafish Assays}

Previous research indicates that melanin pigmentation on the surface of zebrafish is easy to inspect, making it a useful model for studying melanogenesis inhibitors or stimulants in vivo [9]. Zebrafish embryos were incubated in $1 \times$ E3 medium containing 1\% methylene blue as a fungicide at $28{ }^{\circ} \mathrm{C}$.

\subsection{Observation of the Growth and Melanogenesis in Zebrafish Embryos}

To 96-well plates containing 3 zebrafish embryos (7 hpf)/well, $200 \mu \mathrm{L}$ of $1 \times$ E3 medium containing different concentrations of extracts was added. After incubation at $28{ }^{\circ} \mathrm{C}$ for $48 \mathrm{~h}$, the zebrafish embryos were fixed on microscope slides with $2 \%$ carboxymethyl cellulose [7,35]. The morphology of the zebrafish embryos and melanin production were observed and recorded using an inverted microscope (TS100, Nikon, Tokyo, Japan).

\subsection{Assessment of the Viability of Zebrafish Embryos}

To assess the effects of the extracts on zebrafish embryo viability, 3 of the $7 \mathrm{hpf}$ zebrafish embryos / well were plated onto 96-well plates using a dropper. Subsequently, the medium was replaced, and the zebrafish embryos were co-cultured for 2 days in 1× E3 medium supplemented with different concentrations of the extracts. After incubation until $55 \mathrm{hpf}$, the developmental process of zebrafish embryos was observed, and images were captured using an inverted microscope. The viability of zebrafish embryos was calculated as follows: $(\%)=(A / B) \times 100$, where, $A$ and $B$ represent the number of live zebrafish embryos and the total number of zebrafish embryos, respectively. 


\subsection{Analysis of the Heart Rate of Zebrafish Embryos}

Utilizing the methods described in previous studies with a slight modification, the toxic effects of extracts were defined by estimating the heart rate of zebrafish embryos at $55 \mathrm{hpf}$ (total $48 \mathrm{~h}$ of exposure) and compared to that of the non-treatment group [7,36]. Briefly, the medium was removed and the medium containing the extracts was added after incubation until 7 hpf. Next, heart rate was recorded using a camera under an inverted microscope. The counting results were expressed as the average heart rate per minute and calculated as $(\%)=(C / D) \times 100$, where, $C$ and $D$ represent the average heart rate per minute of zebrafish embryos that were co-cultured with and without the samples, respectively.

\subsection{Determination of Melanin Contents in Zebrafish Embryos}

The melanin content assay was performed as described previously, with some modifications $[9,36]$. The zebrafish embryos and extracts were co-cultured using the methods mentioned above. After 2 days of incubation, zebrafish embryos were collected by centrifugation at $1000 \times g$ at $4{ }^{\circ} \mathrm{C}$ for $5 \mathrm{~min}$. Next, the supernatant was removed, the zebrafish embryos were lysed in $1 \times$ lysis buffer and stored at $-20{ }^{\circ} \mathrm{C}$ overnight. The precipitate was then collected by centrifugation at $12,000 \times g$ for $20 \mathrm{~min}$, mixed with $200 \mu \mathrm{L}$ of $1 \mathrm{~N}$ $\mathrm{NaOH}$ and incubated at $95^{\circ} \mathrm{C}$ in a dry bath for $15 \mathrm{~min}$. Finally, absorbance at $405 \mathrm{~nm}$ was recorded, and the melanin content (\%) was calculated as $(\mathrm{E} / \mathrm{F}) \times 100$, where $\mathrm{E}$ represents the absorbance of the extract groups at $405 \mathrm{~nm}$ and $\mathrm{F}$ represents the absorbance of the control group at $405 \mathrm{~nm}$.

\subsection{Statistical Analysis}

All the data in this study were obtained as averages of experiments that were performed at least in triplicate and are expressed as the means \pm standard deviation. Statistical analyses were performed using the Duncan's multiple range method or sample $t$-test with the SPSS 12.0 statistical analysis software (IBM Co. Endicott, NY, USA). A $p$ value $<0.05$ indicated statistical significance.

\section{Results and Discussion}

\subsection{Sprout Length, Germination Rate, and Water Content of 3-Day Germinated Black Soybeans}

According to the research of Kumari et al., after germination for 24,48 , and $72 \mathrm{~h}$, the total phenolic content, total flavonoid content, and antioxidant effects of soybeans and black soybeans were increased, with the highest values observed at $72 \mathrm{~h}$ [37]. Thus, the black soybeans were germinated for $72 \mathrm{~h}$. On the third day of germination, the sprout length of black soybeans reached $3.87 \pm 0.48 \mathrm{~cm}$, with a germination rate of $83.84 \pm 4.07 \%$. After freeze-drying, the water content was determined to be $31.56 \pm 5.51 \%$ (Table 1). According to the minimum germination rate of soybean seeds of $80 \%$ as specified by the Association of Official Seed Certifying Agencies (AOSCA) [38], the black soybeans were well germinated under the cultivation conditions used in this study.

Table 1. The sprout length, germination rate, and water content of 3-day germinated black soybeans.

\begin{tabular}{cc}
\hline Items & 3-Day Germinated Black Soybeans \\
\hline Sprout length $(\mathrm{cm})$ & $3.87 \pm 0.48$ \\
Germination rate $(\%)$ & $83.84 \pm 4.07$ \\
Water content $(\%)$ & $31.56 \pm 5.51$ \\
\hline
\end{tabular}

The data are presented as means $\pm \mathrm{SD}(n=3)$.

\subsection{Changes in the Growth, $p H$ Value, and Titratable Acidity of Germination Black Soy Milk Fermented with TWK10}

In this study, TWK10 was inoculated into nongermination or germination black soy milk, and the changes in the bacterial count, $\mathrm{pH}$, and titratable acidity were measured at different time points. The results showed that there were no significant inter-group differences in the bacterial count at the initial inoculation stage $(p>0.05)$, but the TWK10 
bacterial count in the germination black soy milk group was significantly higher than that in the nongermination black soy milk after 12,24 , and $48 \mathrm{~h}$ of fermentation $(p<0.05$; Figure 1A). This result suggested that the enzymes in the black soybeans were activated during germination, changing the nutritional composition such that the LAB could more effectively utilize the components for growth, thus increasing the bacterial count [39].

(A)

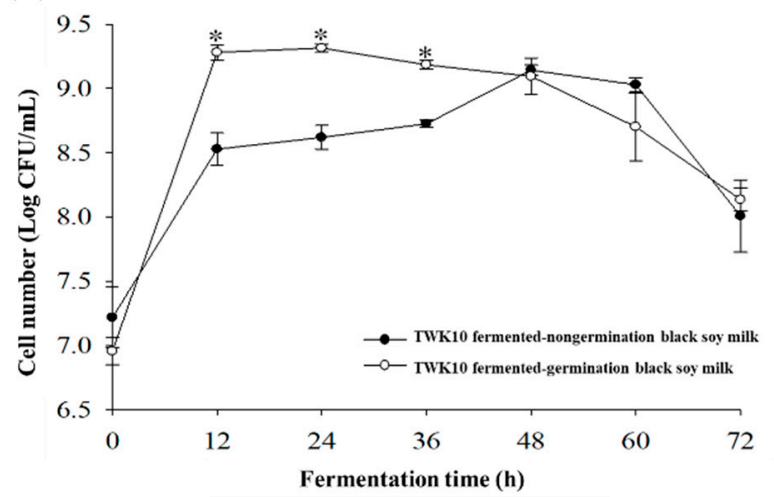

(B)

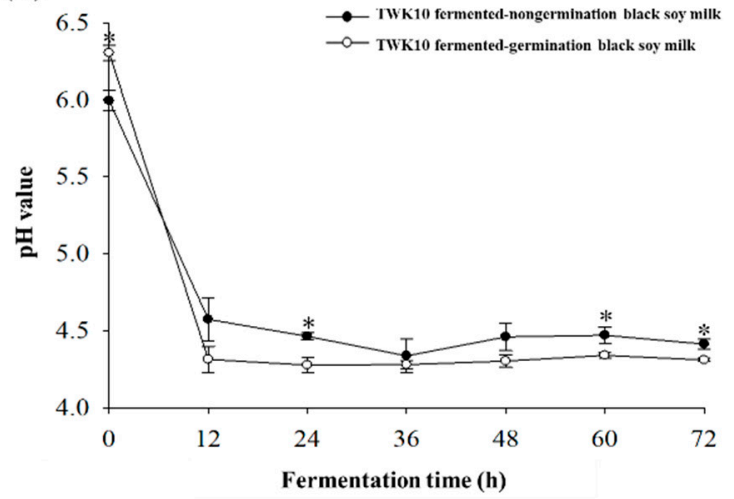

(C)

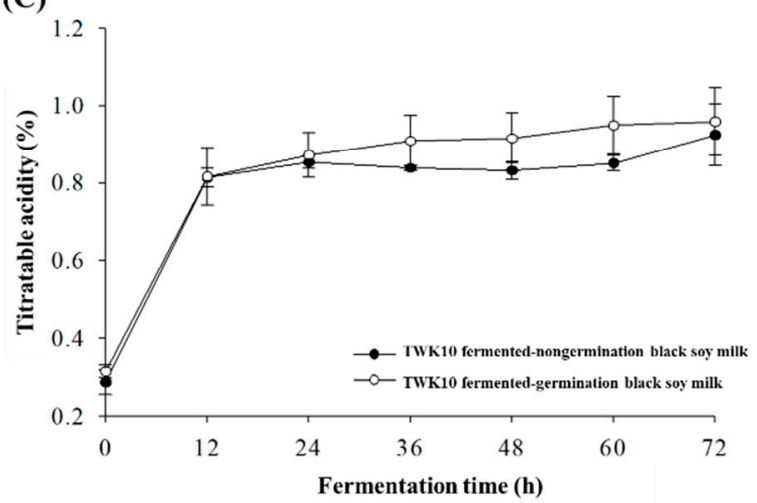

Figure 1. The growth curve (A), pH value (B) and titratable acidity (C) of TWK10 fermentednongermination $(\bullet)$ or TWK10 fermented-germination $(\bigcirc)$ black soy milk. The data are presented as means $\pm \mathrm{SD}(n=3) .{ }^{*}$ represent significantly difference $(p<0.05)$ according to a Sample $t$-test.

The $\mathrm{pH}$ changes are shown in Figure 1B. The initial $\mathrm{pH}$ values of fermented-nongermination black soy milk and fermented-germination black soy milk were 6.00 and 6.30, respectively. After $12 \mathrm{~h}$ of incubation, the $\mathrm{pH}$ of the two groups were significantly reduced by 1.43 and $1.99(p<0.05)$, and the $\mathrm{pH}$ decline stabilized after $12 \mathrm{~h}$. Further measurements were made on the titratable acidity. The initial titratable acidity of fermented-nongermination black soy milk and fermented-germination black soy milk was $0.29 \%$ and $0.31 \%$, respectively, which significantly increased to $0.81 \%$ and $0.82 \%$ after $12 \mathrm{~h}$ of fermentation $(p<0.05$; Figure $1 \mathrm{C})$, before subsequently stabilizing. Lactic acid is produced by lactobacillus during fermentation. Therefore, the titratable acidity of nongermination black soy milk and germination black soy milk in this study increased significantly after the $12 \mathrm{~h}$ of fermentation, while the $\mathrm{pH}$ decreased significantly to $4.30-4.60(p<0.05)$.

The powder of NNGB, FNGB, NGB, and fermented-germination black soy milk (FGB) was extracted with water or ethanol and was subsequently freeze-dried to determine the recovery rate. The results showed that among nongermination black soy milks, the recovery rates of water extracts from nonfermented and fermented groups were $15.55 \pm 2.55 \%$ and $13.52 \pm 0.86 \%$, respectively, whereas among germinated black soy milk, the recovery rates of water extracts from nonfermented and fermented groups were $22.08 \pm 3.64 \%$ and $17.02 \pm 1.00 \%$, respectively. In addition, among nongerminated black soy milks, the recovery rates of ethanol extracts from unfermented and fermented groups were $2.78 \pm 0.83 \%$ 
and $4.77 \pm 0.21 \%$, respectively. Conversely, among germination black soy milks, the recovery rates of ethanol extracts from nonfermented and fermented groups were $4.53 \pm 0.25 \%$ and $7.70 \pm 0.21 \%$, respectively. As seen from the above results, fermentation with TWK10 significantly increased the recovery rate of ethanol extracts for both nongermination black soy milk and germination black soy milk (data not shown).

\subsection{Total Phenolic Content and Total Flavonoid Content}

Figure 2A shows the TPC of the water extracts of NNGB, FNGB, NGB, and FGB, which were $21.79 \pm 0.22,13.88 \pm 0.61,30.83 \pm 0.24$, and $27.82 \pm 0.59 \mathrm{mg} \mathrm{GAE} / \mathrm{g}$, respectively. These results indicate a significant decline in the TPC of the water extracts after fermentation of both nongermination black soy milk and germination black soy milk $(p<0.05)$. In addition, the TPC of the ethanol extracts of NNGB and FNGB were $35.01 \pm 1.73 \mathrm{mg} \mathrm{GAE} / \mathrm{g}$ and $42.66 \pm 1.65 \mathrm{mg} \mathrm{GAE} / \mathrm{g}$, respectively. The TPC of the ethanol extracts of black soy milk increased significantly by $21.85 \%$ after fermentation $(p<0.05$; Figure $2 \mathrm{~B})$. The TPC of the ethanol extracts of NGB and FGB were $47.48 \pm 0.15 \mathrm{mg} \mathrm{GAE} / \mathrm{g}$ and $45.78 \pm 0.88 \mathrm{mg}$ $\mathrm{GAE} / \mathrm{g}$, respectively, with no significant inter-group differences $(p>0.05)$. In summary, the ethanol extracts of NGB and FGB contained the highest TPC.

(A)

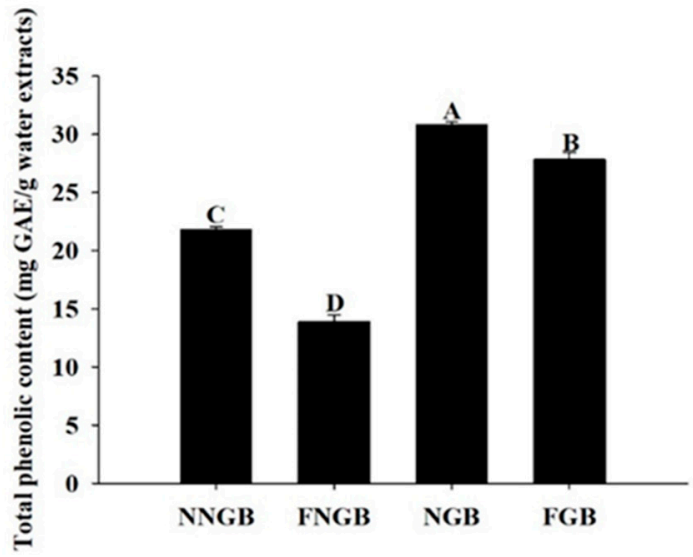

(C)

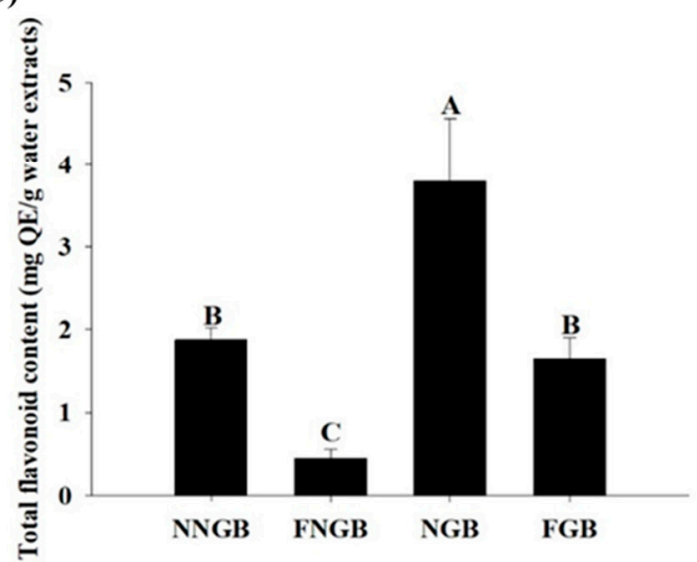

(B)

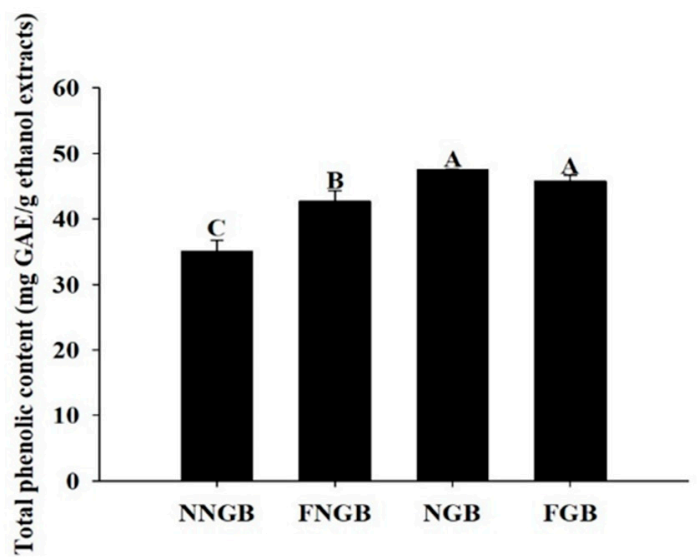

(D)

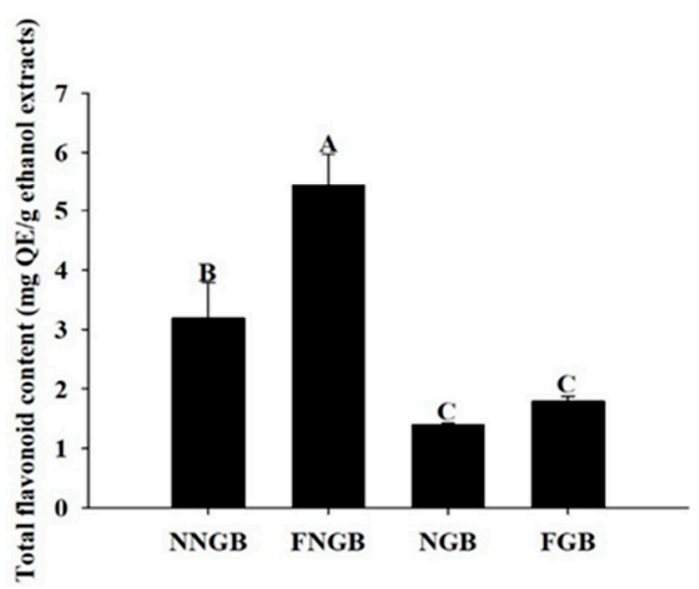

Figure 2. Total phenolic contents (A,B) and total flavonoid contents $(\mathbf{C}, \mathbf{D})$ in the water $(\mathbf{A}, \mathbf{C})$ and ethanol (B,D) extracts of nonfermented-nongermination black soy milk, fermented-nongermination black soy milk, nonfermented-germination black soy milk, and fermented-germination black soy milk. Data are presented as means $\pm \mathrm{SD}(n=3)$. Values with different uppercase letters were significantly different based on Duncan's multiple range test $(p<0.05)$. NNGB, nonfermented-nongermination black soy milk; FNGB, fermented-nongermination black soy milk; NGB, nonfermented-germination black soy milk; FGB, fermented-germination black soy milk; GAE, gallic acid equivalent; QE, quercetin equivalent. 
Further measurements were carried out on the TFC of different samples, and the results are shown in Figure 2C,D. The TFC of the water extracts of NNGB, FNGB, NGB, and FGB were $1.88 \pm 0.15 \mathrm{mg}$ quercetin equivalent $(\mathrm{QE}) / \mathrm{g}, 0.45 \pm 0.11 \mathrm{mg} \mathrm{QE} / \mathrm{g}, 3.80 \pm 0.76 \mathrm{mg}$ $\mathrm{QE} / \mathrm{g}$, and $1.65 \pm 0.25 \mathrm{mg} \mathrm{QE} / \mathrm{g}$, respectively (Figure 2C). This indicates that the TFC of the water extracts decreased significantly after fermentation with TWK10 $(p<0.05)$, which was similar to the previous phenolic content results. In addition, compared with the ethanol extract of NNGB $(3.19 \pm 0.60 \mathrm{mg}$ QE/g), the TFC of FNGB ethanol extract $(5.43 \pm 0.54 \mathrm{mg} Q \mathrm{QE} / \mathrm{g})$ increased by $70.22 \%(p<0.05$; Figure 2D). Among the ethanol extract groups of germination black soy milk, FGB $(1.79 \pm 0.08 \mathrm{mg}$ QE/g) contained a higher level of total flavonoids compared with the NGB ethanol extract $(1.40 \pm 0.03 \mathrm{mg} Q E / \mathrm{g})$. According to the above results, the TFC in the ethanol extracts of nongermination and germination black soy milk increased after fermentation with TWK10.

During soy milk fermentation with lactobacillus, $\beta$-glucosidase hydrolyzes aglyconecontaining isoflavones, such as daidzin and genistin, into the deglycosylated isoflavones daizein and genistein [40]. In terms of solubility, daizdin, genistin, and glycitin had a higher hydrophilicity and are more easily soluble in water [41,42], while aglycone-containing compounds such as genistein had a higher affinity for ethanol [43]. Therefore, it could be speculated that the significant decrease in the TPC and TFC in the water extracts of NNGB, FNGB, NGB, and FGB after fermentation $(p<0.05)$ was caused by glucoside hydrolysis into aglycone-containing compounds.

\subsection{Free Radical DPPH Scavenging Capacity}

Metabolism produces free radicals. When oxidative stress in the body increases and the free radical content is significantly high, damage to the surrounding enzymes, proteins, and the intranuclear DNA occurs, leading to phenomena such as aging and pigmentation [44]. The results showed that the DPPH free radical scavenging capacity of the water extracts of NNGB, FNGB, NGB, and FGB increased with the increase in sample concentration and had a dose-response relationship ( $p<0.05 ;$ Table 2$)$. When the sample concentration was $10 \mathrm{mg} / \mathrm{mL}$, the percentages of DPPH free radicals scavenged by the water extracts of NNGB, FNGB, NGB, and FGB were $43.24 \pm 4.64 \%, 44.24 \pm 1.45 \%, 67.35 \pm 9.87 \%$, and $66.48 \pm 2.97 \%$, respectively. The water extract of germination black soy milk significantly increased the capacity of scavenging DPPH free radicals by $22.24-24.11 \%(p<0.05)$ and had better antioxidant activity, as compared to nongermination black soy milk. When the concentration of the ethanol extracts of NNGB, FNGB, NGB, and FGB was $10 \mathrm{mg} / \mathrm{mL}$, the percentages of DPPH free radicals scavenged were $72.87 \pm 2.14 \%, 83.84 \pm 1.62 \%$, $77.15 \pm 3.80 \%$, and $78.73 \pm 2.44 \%$, respectively (Table 2 ). In addition, ascorbic acid (ASA) was used as a positive control in this study. No significant differences were observed in the DPPH free radical scavenging capacity of the ethanol extracts of FNGB and FGB from the positive control group $(p>0.05)$, indicating that the FNGB and FGB ethanol extract had good antioxidant activity.

Previous studies have suggested that germination increases the production of soluble proteins and biologically active substances such as free amino acids and oligopeptides in edible seeds. In addition, germination soybeans have higher antioxidant activity [45]. Therefore, in the water extract groups, germination black soy milk contained more watersoluble substances and therefore had better antioxidant capacity than nongermination black soy milk. Germination can increase the content of nitrogenous substances, sugars, peptides, free amino acids, and total phenols in the soybean water extract and was associated with the increase of antioxidant capacity [17]. Previous studies have indicated that the ethanol extract of soy milk fermented with TWK10 had a good antioxidant capacity and could significantly improve the chelation of ferrous ions, scavenging of DPPH free radicals, and the total reducing capacity [24]. The results of this study also suggest that the ethanol extracts of NNGB, FNGB, NGB, and FGB had a higher antioxidant activity than water extracts, with the FNGB and FGB ethanol extracts having the strongest antioxidant activities, which was consistent with the literature results. After the assessment of the 
above experiments, the ethanol extract was used as the main sample for the melanogenesis test of zebrafish embryos.

Table 2. Scavenging effects of DPPH radicals by ethanol or water extracts of nonfermentednongermination black soy milk, fermented-nongermination black soy milk, nonfermentedgermination black soy milk, and fermented-germination black soy milk.

\begin{tabular}{|c|c|c|c|c|}
\hline \multirow{3}{*}{ Samples } & \multicolumn{4}{|c|}{ Inhibition (\% of Control) } \\
\hline & \multicolumn{3}{|c|}{ Concentrations $(\mathrm{mg} / \mathrm{mL})$} & \multirow{2}{*}{$\begin{array}{c}\text { ASA } \\
(100 \mu \mathrm{g} / \mathrm{mL})\end{array}$} \\
\hline & 10 & 5 & 2 & \\
\hline \multicolumn{2}{|c|}{ Water extracts } & & & \\
\hline NNGB & $43.24 \pm 4.64^{\mathrm{Bb}}$ & $25.93 \pm 1.67 \mathrm{ABc}$ & $10.34 \pm 3.05^{\mathrm{Bd}}$ & \\
\hline FNGB & $44.24 \pm 1.45^{\mathrm{Bb}}$ & $23.35 \pm 1.19^{\mathrm{Bc}}$ & $11.77 \pm 2.33^{\mathrm{ABd}}$ & \\
\hline NGB & $67.35 \pm 9.87 \mathrm{Ab}$ & $31.95 \pm 7.88^{\mathrm{ABc}}$ & $10.52 \pm 7.00 \mathrm{Bd}$ & \\
\hline FGB & $66.48 \pm 2.97 \mathrm{Ab}$ & $35.12 \pm 5.23^{\mathrm{Ac}}$ & $22.49 \pm 4.84 \mathrm{Ad}$ & $8357+076^{a}$ \\
\hline \multicolumn{2}{|c|}{ Ethanol extracts } & & & \\
\hline NNGB & $72.87 \pm 2.14^{\mathrm{Cb}}$ & $52.88 \pm 3.16^{\mathrm{Bc}}$ & $22.28 \pm 4.18 \mathrm{Ad}$ & \\
\hline FNGB & $83.84 \pm 1.62 \mathrm{Aa}$ & $61.98 \pm 2.08 \mathrm{Ab}$ & $24.21 \pm 6.49 \mathrm{Ac}$ & \\
\hline NGB & $77.15 \pm 3.80^{\mathrm{BCb}}$ & $49.50 \pm 1.92^{\mathrm{Bc}}$ & $25.39 \pm 3.14 \mathrm{Ad}$ & \\
\hline FGB & $78.73 \pm 2.44^{\mathrm{Ba}}$ & $54.90 \pm 6.74 \mathrm{ABb}$ & $29.88 \pm 5.75$ Ac & \\
\hline
\end{tabular}

Data are presented as means \pm SD $(n=3)$. Values in the same group with different uppercase letters in the same column and different lowercase letters in the same row were significantly different by Duncan's multiple range test $(p<0.05)$. The ASA is used as the positive control in this experiment, and its data is statistically analyzed with different concentrations of samples in the row. ASA, ascorbic acid; DPPH, 1,1-diphenyl-2-picrylhydrazyl (0.1 $\mathrm{mM}$ ); NNGB, nonfermented-nongermination black soy milk; FNGB, fermented-nongermination black soy milk; NGB, nonfermented-germination black soy milk; FGB, fermented-germination black soy milk.

\subsection{Effect of FNGB and FGB Ethanol Extracts on the Morphology of Zebrafish Embryos}

Antioxidants can reduce excessive reactive oxygen species (ROS) generation caused by ultraviolet and oxidative stress, which may lead to skin-related diseases. Therefore, ROS scavengers or inhibitors, in addition to other antioxidants, have melanogenesis reducing potential [9]. The results displayed that the ethanol extract of germinated black soy milk fermented with TWK10 had higher total phenolic and flavonoid content than the water extract. In addition, in the DPPH free radical scavenging capacity test, the ethanol extracts of FNGB and FGB had better antioxidant activity, with no significant differences in the capacity of scavenging DPPH free radicals from ASA, which was marketed for skin-lightening $(p>0.05)$. Zebrafish embryos produce large amounts of melanin during normal growth and development. Therefore, a zebrafish animal model was used to evaluate the effects of FNGB and FGB ethanol extracts on melanogenesis in its embryos.

The effects of the FNGB and FGB ethanol extracts on the morphology of zebrafish embryos are shown in Figures 3 and 4. No malformation of the zebrafish embryo was observed when the FNGB or FGB ethanol extract concentration was 10-100 $\mu \mathrm{g} / \mathrm{mL}$. However, when treated with $250 \mu \mathrm{g} / \mathrm{mL}$ of FNGB or FGB ethanol extract, curved tails, deformed backs, and enlarged yolk cysts were observed in zebrafish embryos. Based on the preliminary results above, FNGB or FGB ethanol extract concentration of lower than $100 \mu \mathrm{g} / \mathrm{mL}$ would not lead to zebrafish malformations. 
(a)

(b)

(c)

(d)

(e)

(f)

(g)
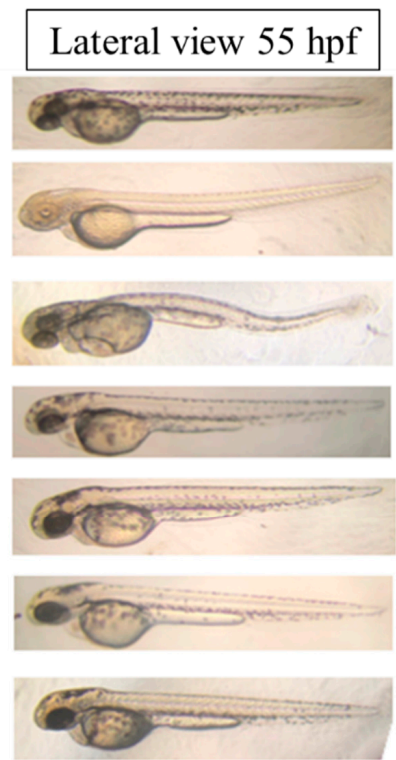

\section{Dorsal view $55 \mathrm{hpf}$}

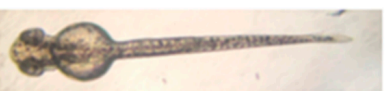

Control

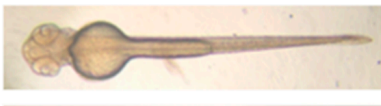

$0.2 \mathrm{mM}$ PTU

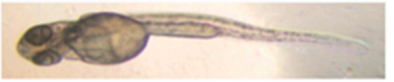

$250 \mu \mathrm{g} / \mathrm{mL}$

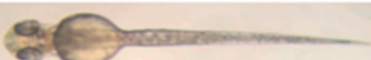

$100 \mu \mathrm{g} / \mathrm{mL}$

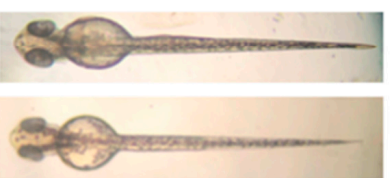

$50 \mu \mathrm{g} / \mathrm{mL}$

$25 \mu \mathrm{g} / \mathrm{mL}$

$10 \mu \mathrm{g} / \mathrm{mL}$

Figure 3. Depigmenting effect of ethanol extracts from fermented-nongermination black soy milk on melanogenesis in zebrafish embryos in an in vivo phenotype-based system. Representative images of synchronized zebrafish embryos treated with ethanol extracts from fermented-nongermination black soy milk at $55 \mathrm{hpf}$ ( $48 \mathrm{~h}$ treatment). Depigmenting efficacy of ethanol extracts from fermentednongermination black soy milk on zebrafish embryos were photographed under a stereomicroscope at the same magnification. PTU, phenylthiourea; hpf, h post fertilization. (a) Zebrafish embryos without treatment as a control, (b) $0.2 \mathrm{mM}$ PTU as a standard positive control, (c) $250 \mu \mathrm{g} / \mathrm{mL}$, (d) $100 \mu \mathrm{g} / \mathrm{mL}$, (e) $50 \mu \mathrm{g} / \mathrm{mL}$, (f) $25 \mu \mathrm{g} / \mathrm{mL}$, and (g) $10 \mu \mathrm{g} / \mathrm{mL}$.

(a)

(b)

(c)

(d)

(e)

(f)

(g)

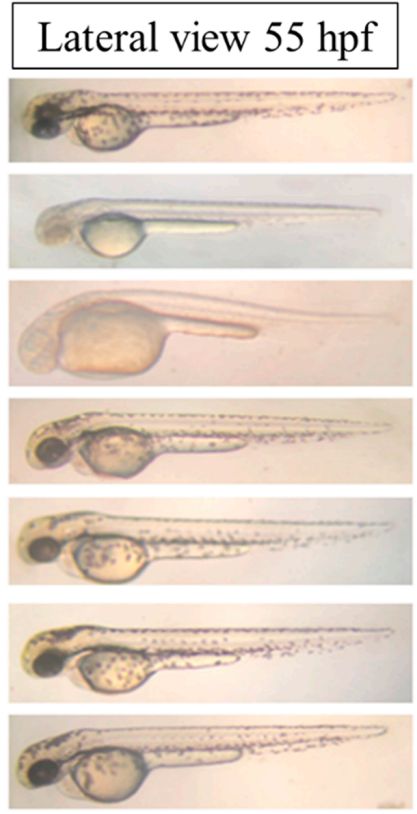

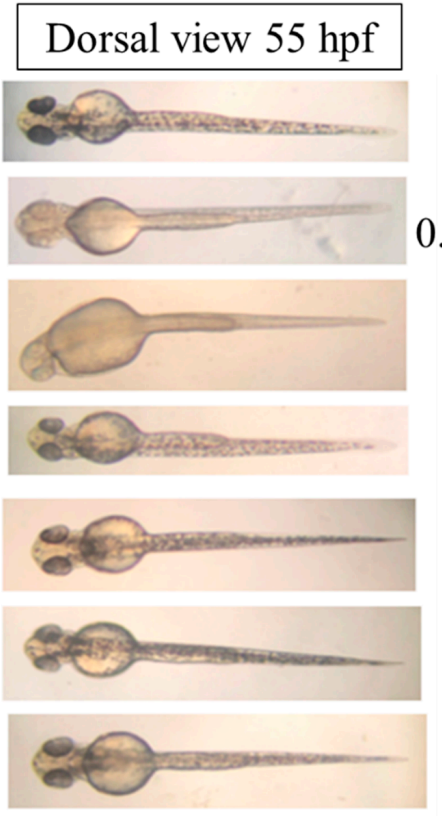

$0.2 \mathrm{mM}$ PTU

$250 \mu \mathrm{g} / \mathrm{mL}$

$100 \mu \mathrm{g} / \mathrm{mL}$

$50 \mu \mathrm{g} / \mathrm{mL}$

$25 \mu \mathrm{g} / \mathrm{mL}$

$10 \mu \mathrm{g} / \mathrm{mL}$

Figure 4. Depigmenting effect of ethanol extracts from fermented-germination black soy milk on melanogenesis in zebrafish embryos in an in vivo phenotype-based system. Representative images of synchronized zebrafish embryos treated with ethanol extracts from fermented-germination black soy milk at $55 \mathrm{hpf}$ ( $48 \mathrm{~h}$ treatment). Depigmentation efficacy of ethanol extracts of fermentednongermination black soy milk in zebrafish embryos were photographed under stereomicroscope at the same magnification. PTU, phenylthiourea; hpf, h post fertilization. (a) Zebrafish embryos without treatment as a control, (b) $0.2 \mathrm{mM}$ PTU as a standard positive control, (c) $250 \mu \mathrm{g} / \mathrm{mL}$, (d) $100 \mu \mathrm{g} / \mathrm{mL}$, (e) $50 \mu \mathrm{g} / \mathrm{mL}$, (f) $25 \mu \mathrm{g} / \mathrm{mL}$, and (g) $10 \mu \mathrm{g} / \mathrm{mL}$. 


\subsection{Effect of FNGB and FGB Ethanol Extracts on the Survival Rate and Heart Rate of Zebrafish Embryos}

In this experiment, besides observing whether the samples would affect the zebrafish embryo morphology, the percentage of deaths and malformations of zebrafish embryos caused by different concentrations should also be assessed. No significant difference in the survival rate of zebrafish embryos was observed compared with that in the control group $(p>0.05)$ when the concentration of FNGB ethanol extract (Figure 5A) or FGB (Figure 5B) was $10-100 \mu \mathrm{g} / \mathrm{mL}$, and the survival rate was between $89.72-100.40 \%$. Meanwhile, under an FNGB or FGB concentration of $250 \mu \mathrm{g} / \mathrm{mL}$, the survival rate of zebrafish embryos was significantly reduced by $78.97 \%$ and $68.77 \%(p<0.05)$, respectively, compared with that in the control group.
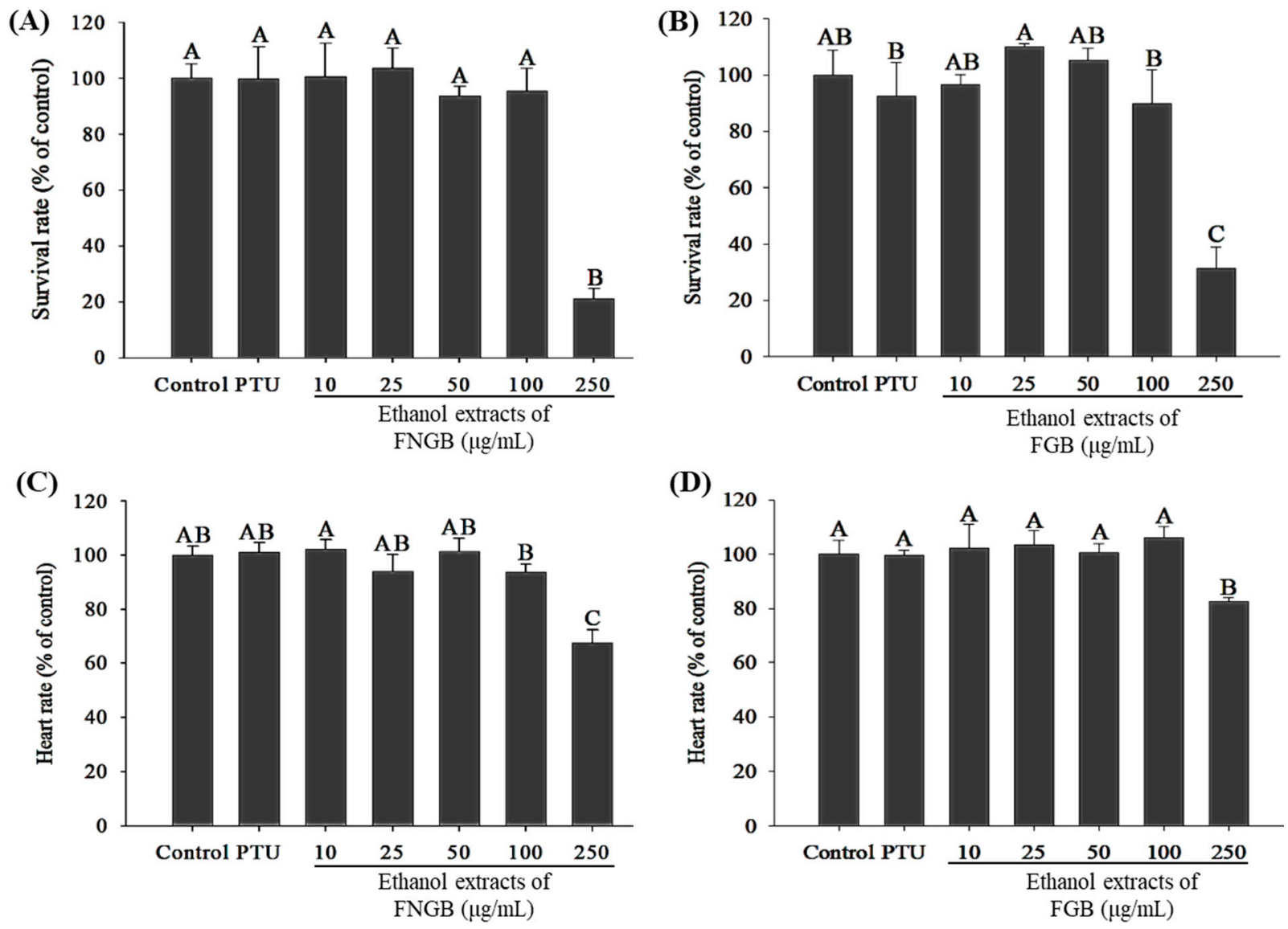

Figure 5. Effects of ethanol extracts from fermented-nongermination black soy milk and fermentedgermination black soy milk on survival rate $(\mathbf{A}, \mathbf{B})$ and heart rate $(\mathbf{C}, \mathbf{D})$ in zebrafish embryos. Zebrafish embryos were treated with several concentrations' ethanol extracts of fermented-nongermination black soy milk or fermented-germination black soy milk $(10-250 \mu \mathrm{g} / \mathrm{mL})$ from 7 to $55 \mathrm{hpf}$. The survival rate and heart rate were determined under an inverted microscope after $48 \mathrm{~h}$ treatment. The data are presented as means $\pm \mathrm{SD}(n=3)$. Values with different uppercase letters were significantly by Duncan's multiple range tests $(p<0.05)$. PTU, $0.2 \mathrm{mM}$ phenylthiourea; hpf, hours post fertilization; FNGB, fermented-nongermination black soy milk; FGB, fermented-germination black soy milk.

During the sample concentration tests on zebrafish embryos, in addition to investigating whether the samples would cause death or malformations of zebrafish embryos, the impact on the heart rate was also observed to ensure the sample applicability. The results are shown in Figure 5C,D. When zebrafish embryos were incubated with FNGB or FGB ethanol extract at $10-100 \mu \mathrm{g} / \mathrm{mL}$, the heart rate was $93.75-102.21 \%$ and $102.12-105.93 \%$, respectively, and there were no significant differences from that in the control group $(p>0.05)$. However, when the sample concentration was $250 \mu \mathrm{g} / \mathrm{mL}$, the heart rate of zebrafish em- 
bryos decreased significantly to $67.28 \%$ and $82.63 \%(p<0.05)$ compared with that in the control group.

In summary, when the concentration of FNGB or FGB ethanol extract was below $100 \mu \mathrm{g} / \mathrm{mL}$, no malformations, death, or decreased heart rate was observed in the zebrafish embryos. Subsequent experiments would use $100 \mu \mathrm{g} / \mathrm{mL}$ as the upper limit concentration of the treatment group.

\subsection{Effect of FNGB and FGB Ethanol Extracts on Melanogenesis in Zebrafish Embryos}

In this study, phenylthiourea (PTU) was used as the positive control group. Results showed that the melanin content of zebrafish embryos treated with PTU was significantly reduced by approximately $57.88-67.67 \%$ compared with that in untreated zebrafish embryos ( $p<0.05$; Figure 6), while after treatment with FNGB ethanol extract at 10, 25, 50, and $100 \mu \mathrm{g} / \mathrm{mL}$, the melanin content in zebrafish embryos significantly decreased by $19.35-25.19 \%(p<0.05$; Figure 6A) compared with that in the control group. In addition, after the zebrafish embryos were incubated with 50 or $100 \mu \mathrm{g} / \mathrm{mL}$ of FGB ethanol extract, the melanin content significantly decreased by $15.50 \%$ and $32.89 \%$ compared with that in control group, respectively ( $p<0.05$; Figure 6B). In summary, when zebrafish embryos were incubated with ethanol extracts of FNGB and FGB at below $100 \mu \mathrm{g} / \mathrm{mL}$, melanogenesis was inhibited without causing malformations, death, or decreased heart rate in zebrafish embryos.

(A)

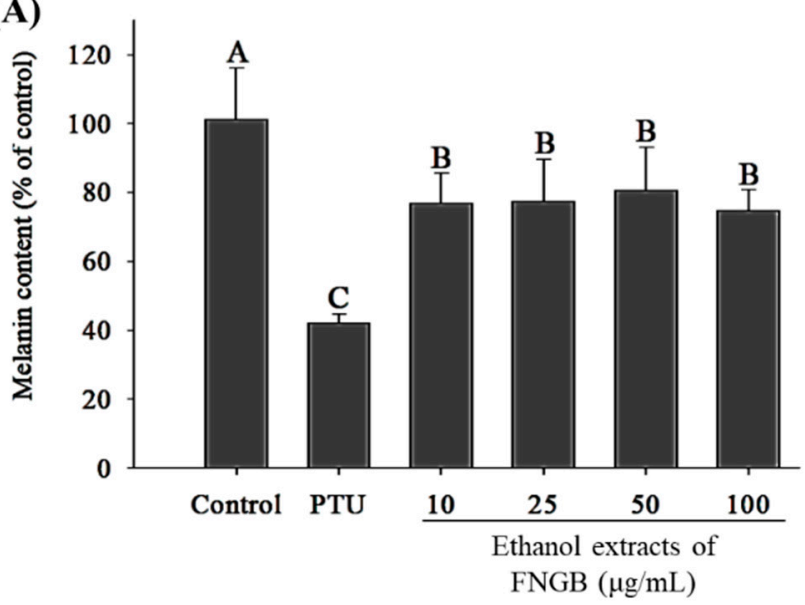

(B)

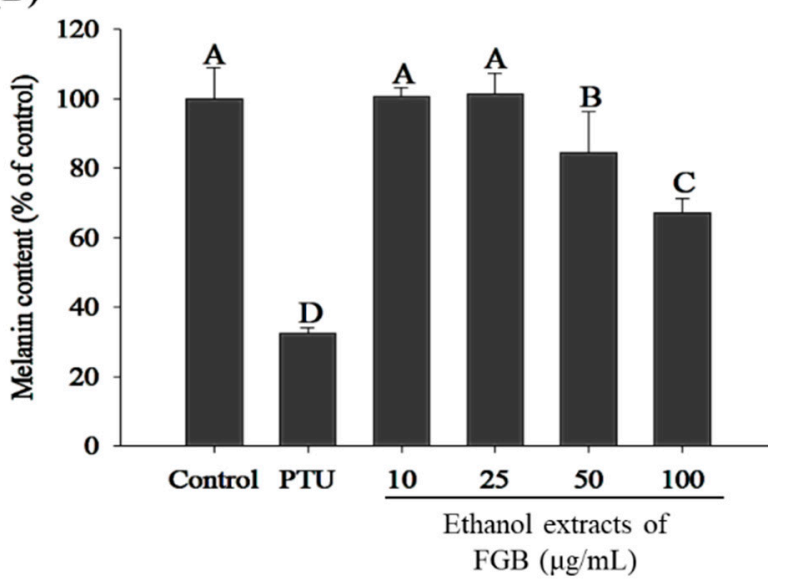

Figure 6. Effects of ethanol extracts of fermented-nongermination black soy milk (A) and fermentedgermination black soy milk (B) on melanin contents in zebrafish embryos. Zebrafish embryos were treated with several concentrations' ethanol extracts of fermented-nongermination black soy milk or fermented-germination black soy milk (10-100 $\mu \mathrm{g} / \mathrm{mL})$ from 7 to $55 \mathrm{hpf}$. Melanin was dissolved with $1 \mathrm{~N} \mathrm{NaOH}$ at $100{ }^{\circ} \mathrm{C}$. The data are presented as means $\pm \mathrm{SD}(n=3)$. Values with different uppercase letters were significantly different based on Duncan's multiple range tests $(p<0.05)$. PTU, $0.2 \mathrm{mM}$ phenylthiourea; hpf, hours post fertilization; FNGB, fermented-nongermination black soy milk; FGB, fermented-germination black soy milk.

\section{Conclusions}

In conclusion, after fermentation with TWK10, the ethanol extract of black soy milk had higher TPC. In addition, the TFC in the ethanol extract of FNGB was significantly higher than that in the nonfermented group and had favorable antioxidant activity. These results indicated that the values of black soy milk were increased via increasing the compound which had anti-oxidative activities after TWK10 fermentation. Furthermore, the ethanol extract of FGB reduced the melanin contents in zebrafish embryos and without causing malformations, death, or decreased heart rate. Our results strongly suggest that ethanol extract of FGB had the potential to be developed as a health-keeping ingredient with skin-lightening effects. In the future, the main active ingredients in the ethanol extract 
of FGB that inhibited melanogenesis will be further separated and purified to explore its mechanism of action.

Author Contributions: T.-Y.T. designed the experiments and contributed the experimental reagents and materials; M.-C.C. analyzed the data and interpreted the results; T.-H.L. carried out the laboratory experiments and wrote this manuscript text; W.-T.C. performed experimental research and analyzed the data. All authors have read and agreed to the published version of the manuscript.

Funding: This research received no external funding.

Institutional Review Board Statement: The study was conducted according to the guidelines of the care and use of laboratory animals and approved by the Institutional Animal Care and Research Ethics Committee of Fu Jen Catholic University (IACUC approval No: A10813).

Acknowledgments: This research did not receive any specific grant from funding agencies in the public, commercial, or not-for-profit sectors.

Conflicts of Interest: The authors declare no conflict of interest.

\section{References}

1. Slominski, A.; Tobin, D.J.; Shibahara, S.; Wortsman, J. Melanin pigmentation in mammalian skin and its hormonal regulation. Physiol. Rev. 2004, 84, 1155-1228. [CrossRef]

2. Bonaventure, J.; Domingues, M.J.; Larue, L. Cellular and molecular mechanisms controlling the migration of melanocytes and melanoma cells. Pigment Cell Melanoma Res. 2013, 26, 316-325. [CrossRef] [PubMed]

3. Pillaiyar, T.; Manickam, M.; Jung, S.H. Downregulation of melanogenesis: Drug discovery and therapeutic options. Drug Discov. Today 2017, 22, 282-298. [CrossRef]

4. Togsverd-Bo, K.; Philipsen, P.A.; Hædersdal, M.; Wulf, H.C.O. Skin autofluorescence reflects individual seasonal UV exposure, skin photodamage and skin cancer development in organ transplant recipients. J. Photochem. Photobiol. B 2018, 178, 577-583. [CrossRef] [PubMed]

5. Kim, M.Y.; Lee, H.E.; Im, M.; Lee, Y.; Kim, C.D.; Lee, J.H.; Seo, Y.J. Effect of adenosine on melanogenesis in b16 cells and zebrafish. Ann. Derm. 2014, 26, 209-213. [CrossRef]

6. Wang, N.; Hebert, D.N. Tyrosinase maturation through the mammalian secretory pathway: Bringing color to life. Pigment Cell. Res. 2006, 19, 3-18. [CrossRef] [PubMed]

7. Karunarathne, W.A.H.M.; Molagoda, I.M.N.; Kim, M.S.; Choi, Y.H.; Oren, M.; Park, E.K.; Kim, G.Y. Flumequine-mediated upregulation of p38 MAPK and JNK results in melanogenesis in B16F10 cells and zebrafish larvae. Biomolecules 2019, 9, 596. [CrossRef] [PubMed]

8. Kao, Y.Y.; Chuang, T.F.; Chao, S.H.; Yang, J.H.; Lin, Y.C.; Huang, H.Y. Evaluation of the antioxidant and melanogenesis inhibitory properties of pracparatum mungo (lu-do huang). J. Tradit. Complement. Med. 2013, 3, 163-170. [CrossRef] [PubMed]

9. Choi, T.Y.; Kim, J.H.; Ko, D.H.; Kim, C.H.; Hwang, J.S.; Ahn, S.; Kim, S.Y.; Kim, C.D.; Lee, J.H.; Yoon, T.J. Zebrafish as a new model for phenotype-based screening of melanogenic regulatory compounds. Pigment. Cell. Res. 2007, 20, 120-127. [CrossRef]

10. Lv, J.; An, X.; Jiang, S.; Yang, Y.; Song, G.; Gao, R. Protoporphyrin IX stimulates melanogenesis, melanocyte dendricity, and melanosome transport through the cGMP/PKG pathway. Front. Pharm. 2020, 11, 569368. [CrossRef]

11. Kim, M.Y.; Jang, G.Y.; Lee, Y.; Li, M.; Ji, Y.M.; Yoon, N.; Lee, S.H.; Kim, K.M.; Lee, J.; Jeong, H.S. Free and bound form bioactive compound profiles in germinated black soybean (Glycine max L.). Food Sci. Biotechnol. 2016, 25, 1551-1559. [CrossRef]

12. Damián-Medina, K.; Salinas-Moreno, Y.; Milenkovic, D.; Figueroa-Yáñez, L.; Marino-Marmolejo, E.; Higuera-Ciapara, I.; VallejoCardona, A.; Lugo-Cervantes, E. In silico analysis of antidiabetic potential of phenolic compounds from blue corn (Zea mays L.) and black bean (Phaseolus vulgaris L.). Heliyon 2020, 6, e03632. [CrossRef] [PubMed]

13. Cardador-Martínez, A.; Martínez-Tequitlalpan, Y.; Gallardo-Velazquez, T.; Sánchez-Chino, X.M.; Martínez-Herrera, J.; Corzo-Ríos, L.J.; Jiménez-Martínez, C. Effect of instant controlled pressure-drop on the non-nutritional compounds of seeds and sprouts of common black bean (Phaseolus vulgaris L.). Molecules 2020, 25, 1464. [CrossRef]

14. Han, C.; Yang, P. Studies on the molecular mechanisms of seed germination. Proteomics 2015, 15, 1671-1679. [CrossRef] [PubMed]

15. Izumi, T.; Piskula, M.K.; Osawa, S.; Obata, A.; Tobe, K.; Saito, M.; Kataoka, S.; Kubota, Y.; Kikuchi, M. Soy isoflavone aglycones are absorbed faster and in higher amounts than their glucosides in humans. J. Nutr. 2000, 130, 1695-1699. [CrossRef]

16. Zhang, G.; Xu, Z.; Gao, Y.; Huang, X.; Zou, Y.; Yang, T. Effects of germination on the nutritional properties, phenolic profiles, and antioxidant activities of buckwheat. J. Food Sci. 2015, 80, H1111-H1119. [CrossRef] [PubMed]

17. Bueno, D.B.; da Silva Júnior, S.I.; Seriani Chiarotto, A.B.; Cardoso, T.M.; Neto, J.A.; Lopes dos Reis, G.C.; Glória, M.B.A.; Tavano, O.L. The germination of soybeans increases the water-soluble components and could generate innovations in soy-based foods. LWT 2020, 117, 108599. [CrossRef]

18. Jayachandran, M.; Xu, B. An insight into the health benefits of fermented soy products. Food Chem. 2019, 271, 362-371. [CrossRef] [PubMed] 
19. Juan, M.Y.; Chou, C.C. Enhancement of antioxidant activity, total phenolic and flavonoid content of black soybeans by solid state fermentation with Bacillus subtilis BCRC 14715. Food Microbiol. 2010, 27, 586-591. [CrossRef]

20. Pyo, Y.H.; Jin, Y.J. Monascus-mediated fermentation improves the nutricosmetic potentials of soybeans. Food Sci. Biotechnol. 2016, 25, 883-891. [CrossRef] [PubMed]

21. Chen, Y.M.; Shih, T.W.; Chiu, C.P.; Pan, T.M.; Tsai, T.Y. Effects of lactic acid bacteria-fermented soy milk on melanogenesis in B16F0 melanocytes. J. Funct. Foods 2013, 5, 395-405. [CrossRef]

22. Liu, Y.Y.; Zeng, S.Y.; Leu, Y.L.; Tsai, T.Y. Antihypertensive effect of a combination of uracil and glycerol derived from Lactobacillus plantarum strain TWK10-fermented soy milk. J. Agric. Food Chem. 2015, 63, 7333-7342. [CrossRef]

23. Chuang, Y.C.; Cheng, M.C.; Lee, C.C.; Chiou, T.Y.; Tsai, T.Y. Effect of ethanol extract from Lactobacillus plantarum TWK10-fermented soymilk on wound healing in streptozotocin-induced diabetic rat. AMB Express 2019, 9, 163. [CrossRef]

24. Liu, T.H.; Chiou, J.; Tsai, T.Y. Effects of Lactobacillus plantarum TWK10-fermented soymilk on deoxycorticosterone acetate-saltinduced hypertension and associated dementia in rats. Nutrients 2016, 8, 260. [CrossRef]

25. Liu, T.H.; Lin, W.J.; Cheng, M.C.; Tsai, T.Y. Lactobacillus plantarum TWK10-fermented soymilk improves cognitive function in type 2 diabetic rats. J. Sci. Food Agric. 2020, 100, 5152-5161. [CrossRef]

26. Cheng, C.P.; Tsai, S.W.; Chiu, C.P.; Pan, T.M.; Tsai, T.Y. The effect of probiotic-fermented soy milk on enhancing the NO-mediated vascular relaxation factors. J. Sci. Food Agric. 2013, 93, 1219-1225. [CrossRef]

27. Cheng, M.C.; Lee, T.H.; Chu, Y.T.; Syu, L.L.; Hsu, S.J.; Cheng, C.H.; Wu, J.; Lee, C.K. Melanogenesis inhibitors from the rhizoma of ligusticum sinense in B16-F10 melanoma cells in vitro and zebrafish in vivo. Int. J. Mol. Sci. 2018, 19, 3994. [CrossRef]

28. Lin, P.Y.; Lai, H.M. Bioactive compounds in legumes and their germinated products. J. Agric. Food Chem. 2006, 54, 3807-3814 [CrossRef]

29. Guajardo-Flores, D.; Serna-Saldívar, S.O.; Gutiérrez-Uribe, J.A. Evaluation of the antioxidant and antiproliferative activities of extracted saponins and flavonols from germinated black beans (Phaseolus vulgaris L.). Food Chem. 2013, 141, 1497-1503. [CrossRef]

30. Lee, W.C.; Mahmud, R.; Pillai, S.; Perumal, P.; Ismail, S. Antioxidant activities of essential oil of Psidium guajava L. leaves. APCBEE Procedia 2012, 2, 86-91. [CrossRef]

31. Julkunen-Tiitto, R. Phenolic constituents in the leaves of northern willows: Methods for the analysis of certain phenolics. J. Agric. Food Chem. 1985, 33, 213-217. [CrossRef]

32. Zhao, L.J.; Liu, W.; Xiong, S.H.; Tang, J.; Lou, Z.H.; Xie, M.X.; Xia, B.H.; Lin, L.M.; Liao, D.F. Determination of total flavonoids contents and antioxidant activity of Ginkgo biloba leaf by near-infrared reflectance method. Int. J. Anal. Chem. 2018, 2018, 8195784. [CrossRef]

33. Kao, T.H.; Huang, C.W.; Chen, B.H. Functional components in Luffa cylindrica and their effects on anti-inflammation of macrophage cells. Food Chem. 2012, 135, 386-395. [CrossRef]

34. Yamaguchi, T.; Takamura, H.; Matoba, T.; Terao, J. HPLC method for evaluation of the free radical-scavenging activity of foods by using 1,1-Diphenyl-2-picrylhydrazyl. Biosci. Biotechnol. Biochem. 1998, 62, 1201-1204. [CrossRef]

35. Chen, Y.M.; Su, W.C.; Li, C.; Shi, Y.; Chen, Q.X.; Zheng, J.; Tang, D.L.; Chen, S.M.; Wang, Q. Anti-melanogenesis of novel kojic acid derivatives in B16F10 cells and zebrafish. Int. J. Biol. Macromol. 2019, 123, 723-731. [CrossRef] [PubMed]

36. Hsu, K.D.; Chen, H.J.; Wang, C.S.; Lum, C.C.; Wu, S.P.; Lin, S.P.; Cheng, K.C. Extract of Ganoderma formosanum mycelium as a highly potent tyrosinase inhibitor. Sci. Rep. 2016, 6, 32854. [CrossRef]

37. Kumari, S.; Krishnan, V.; Sachdev, A. Impact of soaking and germination durations on antioxidants and anti-nutrients of black and yellow soybean (Glycine max L.) varieties. J. Plant Biochem. Biotechnol. 2014, 24, 114. [CrossRef]

38. Senaratna, T.; McKersie, B.D. Dehydration injury in germinating soybean (Glycine max L. Merr.) Seeds. Plant Physiol. 1983, 72 , 620-624. [CrossRef]

39. Nkhata, S.G.; Ayua, E.; Kamau, E.H.; Shingiro, J.B. Fermentation and germination improve nutritional value of cereals and legumes through activation of endogenous enzymes. Food Sci. Nutr. 2018, 6, 2446-2458. [CrossRef]

40. Setchell, K.D.; Brown, N.M.; Zimmer-Nechemias, L.; Brashear, W.T.; Wolfe, B.E.; Kirschner, A.S.; Heubi, J.E. Evidence for lack of absorption of soy isoflavone glycosides in humans, supporting the crucial role of intestinal metabolism for bioavailability. Am. J. Clin. Nutr. 2002, 76, 447-453. [CrossRef] [PubMed]

41. Jankowiak, L.; Kantzas, N.; Boom, R.; van der Goot, A.J. Isoflavone extraction from okara using water as extractant. Food Chem. 2014, 160, 371-378. [CrossRef]

42. Fernandez-Lopez, A.; Lamothe, V.; Delample, M.; Denayrolles, M.; Bennetau-Pelissero, C. Removing isoflavones from modern soyfood: Why and how? Food Chem. 2016, 210, 286-294. [CrossRef] [PubMed]

43. Wu, J.G.; Ge, J.; Zhang, Y.P.; Yu, Y.; Zhang, X.Y. Solubility of genistein in water, methanol, ethanol, propan-2-ol, 1-butanol, and ethyl acetate from (280 to 333) K. J. Chem. Eng. Data 2010, 55, 5286-5288. [CrossRef]

44. Halliwell, B.; Gutteridge, J.M. Role of free radicals and catalytic metal ions in human disease: An overview. Methods Enzym. 1990, $186,1-85$

45. Gao, C.; Wang, F.; Yuan, L.; Liu, J.; Sun, D.; Li, X. Physicochemical property, antioxidant activity, and cytoprotective effect of the germinated soybean proteins. Food Sci. Nutr. 2018, 7, 120-131. [CrossRef] 